Int. J. Electrochem. Sci., 16 (2021) Article ID: 210418

International Journal of

ELECTROCHEMICAL

SCIENCE

www.electrochemsci.org

\title{
Microstructure and Corrosion Resistance of Inconel 625 Overlay Welded by Pulsed TIG Process
}

\author{
Longlong Guo ${ }^{1,3}$, Fei Xiao ${ }^{2}$, Fan Wang ${ }^{2}$, Yutian $\mathrm{He}^{1}$, Wenlan Wei ${ }^{1}$, Yong Zhang ${ }^{1}$ \\ ${ }^{1}$ Mechanical Engineering College, Xi'an Shiyou University, Xi'an, 710065, People's Republic of \\ China; \\ ${ }^{2}$ Chongqing Pump Factory Co., Ltd., Chongqing, 400000, People's Republic of China; \\ ${ }^{3}$ Chongqing Engineering Technology Research Center for Light Alloy Materials and Processing, \\ Chongqing, 404000, People's Republic of China; \\ *E-mail: 15108208278@163.com
}

doi: $10.20964 / 2021.04 .11$

Received: 22 November 2020 / Accepted: 5 January 2021 / Published: 28 February 2021

To coordinate the material cost and corrosion resistance of the components served in corrosive environment, Inconel 625 was cladded over the AISI 4130 steel using pulsed tungsten insert gas welding (TIG). The microstructure and corrosion resistance of the Inconel 625 overlay was investigated. The Inconel 625 overlay is mainly composed of $\gamma-\mathrm{Ni}$ matrix and laves precipitate. Increasing layer of the overlay is benefit to reduce the compositions dilution. The content of $F e$ in the second layer overlay is only about $2 \%$. The Nyquist plot of the substrate shows a capacitive loop with a diffusion tail, while that of the Inconel 625 overlay are composed of single capacitive loop. The tested surface near the upper surface of the second layer overlay shows the least charge transfer resistance, but which below the middle surface of the second layer overlay features the largest charge transfer resistance compared with others. The passivation behavior of the Inconel 625 overlay below the middle surface of the second overlay is more stable than others. The specimen near and below the middle surface of the second overlay indicates more outstanding comprehensive pitting corrosion resistance than others. Additionally, seriously uniform corrosion occurred at the specimen of the single layer Inconel 625 overlay. There is no pitting corrosion on the specimens located the second layer of Inconel 625 overlay. Those demonstrated that two layers Inconel 625 overlay can efficiency protect the substrate from corrosion.

Keywords: Inconel 625 overlay, Microstructure, Corrosion resistance, Potentiodynamic polarization, EIS

\section{$\underline{\text { FULL TEXT }}$}

(C) 2021 The Authors. Published by ESG (www.electrochemsci.org). This article is an open access article distributed under the terms and conditions of the Creative Commons Attribution license (http://creativecommons.org/licenses/by/4.0/). 